\title{
Managing m-learning application development: Roles and Responsibilities
}

\author{
Amir Dirin ${ }^{1}$ \\ Business Information Technology, HAAGAHELIA \\ University of Applied Science \\ Helsinki, Finland \\ Amir.dirin@haaga-helia.fi
}

\author{
Marko Nieminen ${ }^{2}$ \\ SorberIT, Aalto University \\ ESPOO, Finland \\ Marko.nieminen@aalto.fi
}

\begin{abstract}
- in this paper we reveal m-learning applications' engaged role-players in various phases of User Centered Design (UCD) framework for m-learning application. Additionally this paper elaborate the contribution of roleplayers to m-learning application at the design and development phases based on UCD framework for m-learning application development. Finlay this paper argues the responsibilities of role-players in UCD framework for mlearning application development process.
\end{abstract}

Keywords-User Centered Design, M-learning application development, role-players,

\section{INTRODUCTION}

Technology has been part of education and educational institutes for some time and will continue to influence students and teachers in their educational activities. The use of ICT in education and training has caused several paradigm shifts. For example, networks offered flexible and powerful new ways to accomplish a range of pedagogical goal [1]. Furthermore, advancements in mobile and wireless technologies in recent years have enabled the learners to carry out some of their educational tasks anywhere at any time. The trend of location-agnostic learning is evolving as the mobile learning is not anymore restricted to class-based learning or virtual learning curricula. Anybody who has a mobile device with access to the internet is a potential student regardless of physical location.

Users role in product concept development are nowadays become more important due to the fact that contemporary software development methodology such as UCD, Lean and agile promote users involvements in product development. This results also mindset changes in traditional project management organizations.

User Centered Design (UCD) principles for example mandates that all users who are involved with product must be identified and involved in the product development. As Garrett [2] pointed out involving the people throughout the organization helps to get as many perspectives as possible on questions of product objectives and user needs.

There are often many role players involved in product concept development then the target or the potential users of the product.
In m-learning application development similarly involve different role players at the various phases of application design and development. This study classifies these role players as direct and indirect role players. Those role players e.g. students and teacher who are involved with the product concept development is considered as direct role players. Those role players e.g. manufacturers, network operators who have often set of constrains and rules that effect indirectly application performance is considered as indirect role players

In this paper stakeholder refers as a direct users of the mlearning application, stakeholders are the users group that we conduct the user studies such as interview etc. Role-player is a general terms that refers to those players who may involves or have impact in m-learning application development.

\section{UCD METHODS \& PROCESS}

User-Centered Design and development of interactive systems and devices has an increasing importance in product development organizations [3]. In addition, UCD is the most common method for developing smart product. Gould [4-5] argued that in a usable system, we need to involve users' continually, and based on user's feedback modify the design. The user-centered design (UCD) cuts both costs [6] and improves usability, since it continually focuses on the essential of the customer needs as early as possible. The user's requirements are the focus in all stages of product development cycle. Human-centered design ISO 9241-210 (2010) Human-cantered design for interactive systems. European Standard [7] processes for interactive system (ISO 13407 Model, 1999) defines three different design solutions for UCD as: I. Cooperative design; designers and the user involved in all stages II. Participatory design; users' occasionally participate in the design process, III. Contextual design; design based on the actual context. Table 1 presents Preece [8] recommendations for users involvements in various stages of the design and developments. 
Table 1 user's involvements in the design and development of a product/artifact [8].

\begin{tabular}{|l|l|l|}
\hline \multicolumn{1}{|c|}{ Technique } & \multicolumn{1}{|c|}{ Purpose } & $\begin{array}{l}\text { Stages of the } \\
\text { design cycle }\end{array}$ \\
\hline $\begin{array}{l}\text { Background } \\
\text { Interview and } \\
\text { Questionnaires }\end{array}$ & $\begin{array}{l}\text { Collecting data related to the } \\
\text { needs and expectation of users; } \\
\text { evaluation of design } \\
\text { alternatives prototypes and the } \\
\text { final artifact }\end{array}$ & $\begin{array}{l}\text { At the } \\
\text { beginning of } \\
\text { the design } \\
\text { project }\end{array}$ \\
\hline $\begin{array}{l}\text { Sequence of } \\
\text { work interviews } \\
\text { and } \\
\text { questionnaire }\end{array}$ & $\begin{array}{l}\text { Collecting data related to the } \\
\text { sequence of work to be } \\
\text { performed with the artifact }\end{array}$ & $\begin{array}{l}\text { Early in the } \\
\text { design cycle }\end{array}$ \\
\hline Focus groups & $\begin{array}{l}\text { Include a wide range of } \\
\text { stakeholders to discuss issues } \\
\text { and requirements }\end{array}$ & $\begin{array}{l}\text { Early in the } \\
\text { the design } \\
\text { cycle }\end{array}$ \\
\hline $\begin{array}{l}\text { On-Site } \\
\text { observation }\end{array}$ & $\begin{array}{l}\text { Collecting information } \\
\text { concerning the environment in } \\
\text { which the artifact will be used }\end{array}$ & $\begin{array}{l}\text { Early in the } \\
\text { design Cycle }\end{array}$ \\
\hline $\begin{array}{l}\text { Role Playing, } \\
\text { walkthroughs, } \\
\text { and simulations }\end{array}$ & $\begin{array}{l}\text { Evaluation of alternative } \\
\text { designs and gaining additional } \\
\text { information about user needs } \\
\text { and expectation; prototype }\end{array}$ & $\begin{array}{l}\text { Early and } \\
\text { mid-point in } \\
\text { the design } \\
\text { cycle }\end{array}$ \\
\hline Usability testing & $\begin{array}{l}\text { Collecting quantities data } \\
\text { related to measurable usability } \\
\text { criteria }\end{array}$ & $\begin{array}{l}\text { Final stage of } \\
\text { the design } \\
\text { cycle }\end{array}$ \\
\hline $\begin{array}{l}\text { Interviews and } \\
\text { questionnaires }\end{array}$ & $\begin{array}{l}\text { Collecting qualitative data } \\
\text { related to user satisfaction with } \\
\text { the artifact }\end{array}$ & $\begin{array}{l}\text { Final stage of } \\
\text { the cycle }\end{array}$ \\
\hline
\end{tabular}

The proposed UCD framework for m-learning application development consists of three main parts, the role-players, the context of use and the processes. This paper reveals the role-players contributions and their responsibilities to share and participate in m-learning application concept development.

This paper is the result of the assessments of User Centered Design Framework for m-learning application development [9]. The assessments mainly carried out by developing m-learning application prototypes as case studies. The processes of UCD for m-learning application development framework are elaborated in next sections. The framework mandates that the stakeholders of m-learning application to be identifies at the elicitations phase. These stakeholders are often directly or indirectly involve in $\mathrm{m}$ learning application development at the various phases of UCD framework for m-learning application development.

\section{M-LEARNING APPLICATION DEVELOPMENT PROCESS}

UCD framework for m-learning application development is an iterative process which consist of different phases. The framework promotes engagement of the potential users group at all phases.

Figure 1 presents the UCD framework for m-learning application development processes.

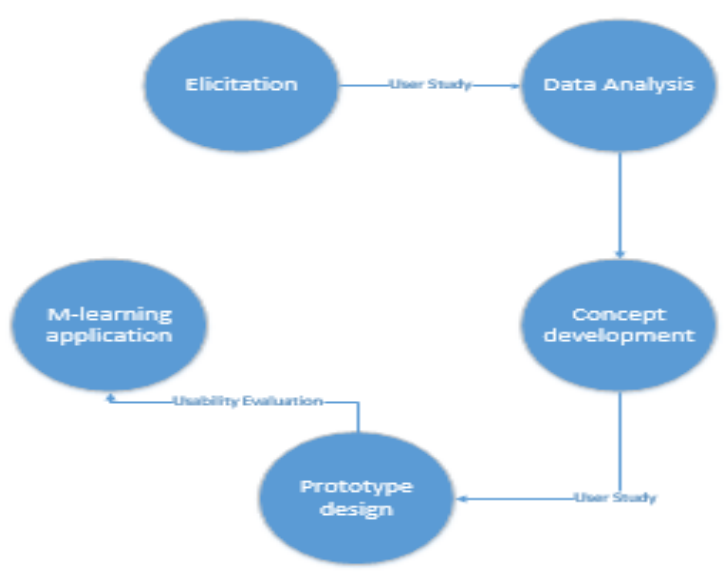

Figure 1. M-learning application development process based on UCD framework for m-learning application development

Elicitation Phase (identify the role-player and understand the users)

This is an important phase in UCD for mobile learning application development. At this phase target role players and stakeholders are identify and their real needs, expectations and constrains are investigated by applying various user study methods such as diary and interview etc. The user study method such as diary helps the designers to learn about the user and their environment that they often interacts. Standard UCD methodology recommends 3-10 target users involvement at various user studies stages [10]. The case studies assessments which is developed based on the proposed UCD confirms that the 4-7 users are enough for m-learning application development.

\section{Data Analysis phase (Identifying the interactions)}

In this phase the collected data from previous phase is analyzed by applying various data analysis techniques such as transcript coding, user task and environment analysis. These methods help to learn about how currently users handle the educational activities, where they handle often their tasks and what they expected from m-learning application. Finally, by using affinity diagram the list of actions and requirements that are resulted from analysis are categorized and prioritized.

\section{Concept development phase (Producing design Solution)}

At this phase we confirm the categorized and prioritized requirements with the potential test users through scenario design. The scenario is given to user for review and assessment. This step ensures that the designers understood the users' needs properly and the scenario help the user to impact to the overall application once again. We present the categorized requirements as scenarios. Scenario is the best approach that we promote in mobile learning application concept design. As scenario speaks user's language and often avoid technical terms and complexities. 
Prototype design (Evaluating the designs)

In this phase the application concept is modified based on the gathered feedback data from scenario review sessions. The application concept is now ready to be implemented as non-functional prototype. The prototype consists of the potential user interface components and the navigations of various screens. The last stage of users' involvement in the design process we conduct usability evaluation test for the proposed application prototype. The target application design refinement is based on the usability test results

\section{ROLE-PLAYERS IN M-LEARNING APPLICATION DEVELOPMENT}

Our Framework for user centered design framework for m-learning Application Development [9] mandates the identification of the stakeholders involved in m-learning application development. Similarly as ISO 9124 standards [11] imply important characteristics of such framework are the stakeholders who are also involved in m-learning application development.

\section{A. Identified Role-Players}

The following roles are identified as potential players in m-learning application development. These roles impact directly or indirectly on the development, utilization, and usage of mobile learning application. These roles mainly have been identified during previous study [12] but in the UCD framework for m-learning processing extensively elaborated.

The identified roles in m-learning application are categorized in four distinct groups.

Direct role-player

1. Students

2. Teachers

3. Course admin and assistants

4. Educational Institutes

Indirect role-player

1. Educational Institutes and administrators

2. App designers

Visible role-player

1. E-learning platform

2. Operators

3. Mobile device

Invisible role-player

1. Manufacturer

Figure 2 presents the role player groups and their recognitions at the elicitation phase.

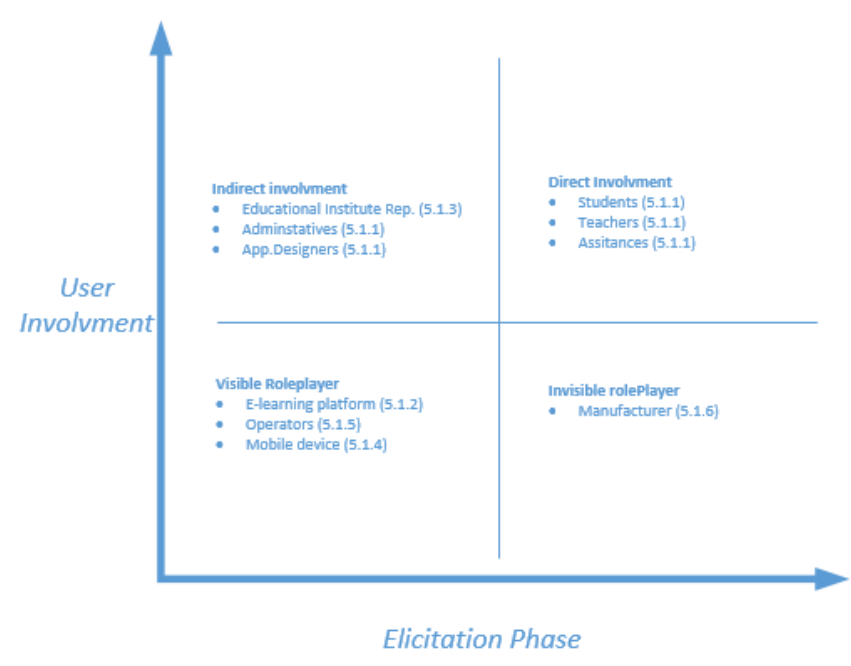

Figure 2. M-learning role-player at Elicitation Phase

\section{B. Role-Players Contribution}

This section describes the contributions of role players in $\mathrm{m}$ learning application development.

- $\quad$ Students are the key players in m-learning application [13] Student in this study refers to a person who uses the mobile learning application to learn and carry the basic educational activities through mobile device such as smart phone. Additionally, student in this study refers to a person who study at the higher educational institutes such as universities or university of applied science. Mobile learning application aims to accomplish students' needs and expectations in contemporary educational settings. Students' expectations differ based on the context and the content of the target course. There are, however, generic expectations such as having access to course content remotely or to perform and carry the essential educational activities on their mobile. Student as a target user of the application can help the designers to define the content, to reveal in what context they expect to use the application, as a result the m-learning application is considered as learner-specific application. Student needs and requirements are gathered by conducting appropriate user study methods.

- Teachers: are also the key players in m-learning application usage. Teacher in this paper refers to a person who organizes a course, provides content for students and performs other managerial role for the course. The learning material can be text, video, audio, or animations. In the same way as for students, mobile learning applications are considered as essential tools for teachers in their educational activities.

- Course admin and assistants: In higher educational institutes such as academic universities and universities of applied science many courses have assistants to 
support teachers in their course related tasks and support students. Admins have various tasks such as course web site content maintenance and student's assignments answer review etc.

- Educational Institutes and Admin: The contributions of educational institutions into m-learning application offering are summarized as financial support to implement m-learning application and infrastructure. Expert support to design and implement the system. Teacher support to create appropriate content for $\mathrm{M}$ learning application.

Encourage the teaching staff to utilize m-learning application in their teaching portfolio

Indirect role-player

- E-Learning platform: is refers as a platform that provide various courses remotely to students. M-learning is considered as a supportive tool on e-learning platform. Some of m-learning considerations are highlighted as follows: What to display on the gadget such as smart phones by keeping usability [14] in mind. As the content presentations are fundamentally dissimilar from PC counterpart. The m-learning application content presentation is based on the mobile capabilities and features. Privacy and trust are important factors; user requires that the privacy and data exchanged in the system be secured and reliable

- Application designers: Application designers and developers are invisible role-players in the M-learning application utilization. The implementation of an mlearning application requires the involvement of several areas of expertise e.g. user study experts, user experience specialist, concept developers and software developers. These groups are identified as role-players who are not necessarily users of the application. Their contributions to the m-learning application development as development expert is the technology selection for application implementation, functional and usability test of the application and maintenances.

Visible Role player

- Operators: Operators refers to the network providers to the mobile subscribers. Some of the key contributions of the operators to m-learning application are as follows: Application settings in user devices via operator's carrier: setting up all the necessary settings i.e., user account, e-mail and profile configuration requires extensive efforts and technical knowledge. The operators are able to send the configuration files through SMS or as push notification.

Content delivery speed: The main drawback of the mobile learning application usage and m-learning application penetration among students and teachers has been the data transformation speed and the network bandwidth limitation. Nowadays however this is not any more a big concerns as the data transformation speed has increased considerably in $3 \mathrm{G}$ and $4 \mathrm{G}$ network infrastructure. Moreover, mobile devices are equipped with advanced wireless technologies such as wi-fi that connect mobile device to the existing WLAN network with very high speed data connectivity.

By providing fast and reliable data communication to m-learning application operators may influence the user experience of the m-learning application.

Content delivery to users in a cost effective way: Most users of mobile learning application users are students who are financially not very secure [12]. Operators by providing alternative solutions i.e., time of the data transformation or provide $\mathrm{M}$ - learning application for education institutes enable students to use the application in an affordable manner.

Support multi-formatted data exchange and content delivery: The mobile learning application often contains and offers multi-formatted content such as video, audio, pictures etc.

Security and availability: The integrity of the user's data and the mobile learning content delivery ensures user's satisfaction.

- Mobile device and information appliance: Mobile devices and information appliances are indirect but key role players in m-learning application development. These are the devices that the target users of the mlearning application use to connect to interact with mlearning application. Unlike the other role player mobile device is considered as invisible or indirect role player. The m-learning application development team has to consider the fact that the target users may use various mobile device platforms. As a result, the design of the application should support the multi-platform mobile devices.

Invisible Role Player

- Manufacturer: Smart device manufacturers are yet another indirect and invisible contributors to m-learning applications offerings. M-learning application is lacking international standard as in e-learning [15-16]. In contemporary mobile devices the developed third party mobile applications often behave differently in different platforms [14]. There have been many attempts in recent years to overcome this type fragmentation by introducing common development technologies such as HTML5 [14].

\section{CONCLUSION:RESPONSIBILITIES OF M-LEARNING APPLICATION DEVELOPMENT}

UCD mandates that stakeholders who are involved in the design must participate at various phases. They main responsibility is to provide feedback based on the context of the user study methods. In the following the m-learning application stakeholders' responsibilities in m-learning application developments are revealed.

Students' are expected to participate in all phases of the UCD frameworks processes. At the elicitation phase student participates in user study sessions such as interview. Moreover student review the scenarios and provides feedback to designers about the concept at the concept 
development phase. Finally student participates at the final phase of framework processes to carry the usability evaluation of the high fidelity prototype.

Teachers' responsibilities are somehow similar as students in UCD framework. This includes participation in user study session for identifying needs and expectations from teacher's perspective at the elicitation phase. Provide feedback on scenario at the design phase. And finally participate in high-fidelity usability test sessions at the final phase of the UCD framework process.

Application Designers: unlike teachers and students who are the potential users of the application. The application designers mainly responsible for developing the application. They are not necessarily use the application themselves as a potential user. Application Designers' main responsibilities are to gather requirements at the elicitation phase. Set up the data analysis sessions and create list of requirements at the data analysis phase. Write done the scenarios and setup the review sessions with potential users. Record and analysis the data after the scenario review session. Finally design and develop the high fidelity prototype of the application and setup usability test session. Based on the latest findings the application concept is finalized and prepare for implementation. Application designer's responsibility also include the evaluation and selection of proper technologies for application implementation. Additionally the designer should learn about the smarts device, operators, e-learning platforms and educational institutes, contributions, constrains and rules which may impact the application implementation and usages.

Educational institutes: Educational institute's responsibilities mainly associated with financial support, development support and utilization (legitimacy) supports. With these supports application successes and penetration is ensured.

Operators, e-learning platform and Manufacturer: These role players' responsibility especially in application development is ambiguous. These players often have set of constrains and rules that impact the application implementation which the application developers need to learn and apply in the application implementation.

The users' motivation factors to engaging in various phases of the UCD framework for m-learning application are not yet investigated. The motivation factors is important to study and recognize. The overall application usability and user experience is depends how actively the potential users involve in application development stages. As a future work this study will continue to reveal the possible factors that encourage users to participate actively in user studies sessions at the various phases of UCD framework processes.

\section{REFERENCES}

[1] Bransford, John,D., Brown, Ann, L., Rodney, R., \& Cocking.,. How people learn: Brain, Mind, Experience, and School. National Academy press, Washington, D.C. 1998, USA

[2] Garrett, James., Elements of User Experience, The User-Centered Design for Web and Beyand, 2010

[3] Nieminen, Marko., 2004. Information Support for User-Oriented Development Organisation- Considerations Based on the Construction and Evaluation of Knowledge Storage, ISBN 951-227308-X

[4] Gould, J,D., \& Lewis, C., 1985. Designing for Usability: Key Principles and What Designers Think. Comm.ACM, 28(3), 1985. 300-311

[5] Gould, J.D., Boies, S,J., \& Ukelson, J., 1997. How to Design Usable Systems. In M.G.Helander, T.K.Landauer and P.V. Prasad eds. Handbook of Human-Computer Interaction. Amsterdam, Netherlands: Elsevier Science/North Holland, 1997

[6] Bosert, J.L., 1991. Quality Functional Deployment: A Practitioner's Approach. ASQC Quality Press. New York. http://rapiddigger.com/download/quality function-deployment-apractitioner-s-approach-bossert-j-1-1991-pdf-rar-3637007/ [ Accessed 20 May 2010]

[7] ISO 9241-210 (2010) Human-centered design for interactive systems. European Standard.

[8] Preece, J.; Rogers, Y., \& Sharp, H. (2002) Interaction design: Beyond human-computer interaction. New York: John Wiley \& Sons, Inc.

[9] Dirin, Amir., Nieminen, Marko., 2013. State-of-the-art of M-learning usability and user experience. The Fourth International Conference on e-Learning (ICEL). Ostrava, Czech Republic 201 8-11 July.

[10] UCD NO:

[11] ISO 9124 standards (parts 11, 1998 and 210, 2010)

[12] Mostakhdemin-Hosseini Ali, Tuimala, Jarno "Mobile Learning Framework" , International association for development of Information Society, July 17-19th, 2005, Qawra, Malta

[13] Mostakhdemin-Hosseini Ali, 2008, "Analysis of Pedagogical Considerations of m-learning in smart devices". Published June 2009 at International Journal of Interactive Mobile Technologies (iJIM) Volume 3, Special Issue 1: "IMCL 2009"

[14] Dirin Amir, Nieminen Marko, Kettunen Mirka, 2013. Students capabilities to utilize m-learning service in new smart phones. 2013 International Conference on Advanced ICT for Education (ICAICTE 2013) September 20-22, 2013 Hainan, China.

[15] Ileana Adina. "E-learning standards." Informatica Economica Journal 1 (2007): 41.

[16] Stratakis, Miltos, et al. "E-Learning Standards." SeLeNe (Self E-Learning Networks IST-2001-39045), Project Deliverable 2 (2003 